\title{
Safety Audits at Finnish Level Crossings
}

\author{
Veli-Pekka Kallberg ${ }^{*}, 1$, Antti Seise ${ }^{1}$, Jouni Hytönen ${ }^{2}$ and Tapio Ahonen ${ }^{1}$ \\ ${ }^{1}$ VTT Technical Research Centre of Finland, Finland \\ ${ }^{2}$ Finnish Transport Agency, Finland
}

\begin{abstract}
Safety audits of Finnish level crossings have been carried out for 10 years at an average pace of 400 level crossings per year. Altogether 3863 level crossings have been audited - more than $95 \%$ of all level crossings on the state railways. The objective of the audits is to improve safety at level crossings so that vigilant and motivated road users can cross the railway safely. The audits include systematic and extensive at-site recording of the physical characteristics of the level crossing, description of traffic on the railway and the road, a number of photographs, and recently also video clips. The main output from the audits consists of recommendations for safety measures. The data collected can also be used for statistical analysis, such as calculation of the safety index for individual level crossings. A PC application for viewing the data, photos and video clips of individual level crossings is a handy tool for those responsible for level crossing management.
\end{abstract}

Keywords: Level crossing, grade crossing, safety.

\section{INTRODUCTION}

At the end of 2009 there were 3376 level crossings on the state railways in Finland, with an additional 685 on private rails. Altogether 740 level crossings were provided with barriers (usually half-barriers), 78 with a light and sound warning device, and 17 with a simple light warning device. The remaining 3226 level crossings were equipped with passive warning signs, usually a St. Andrew's cross only.

The number of level crossings on state railways has been cut to less than half since the mid-1970s, when the total number was about 8000 . At the same time the number of level crossings with active warning devices - usually halfbarriers - has doubled, and about 200 light and sound warning devices have been replaced with half-barriers [1].

Even though the number of level crossings has decreased and the number of level crossings with active warning devices has increased significantly, accidents at level crossings remain a major safety issue for Finnish railways despite the fact that the annual number of fatalities in level crossing accidents has dropped from around 50 to 10 since the early 1970s [2]. Nowadays, roughly 50 accidents occur at level crossings every year. Most accidents occur at passive level crossings where road and rail traffic volumes are low, typically less than 20 trains and road vehicles per day.

In almost all fatal level crossing accidents in 1991-2004, the road vehicle ran to the level crossing without stopping [3]. The driver's inappropriate behaviour was in most cases explained by erroneous observation (58\%) and anticipation and assessment errors (28\%). The driver's inappropriate behaviour was moreover explained by the familiarity of the

*Address correspondence to this author at the P.O. Box 1000, FIN-02044 VTT, Finland; Tel: +358 20722 4591; Fax: +358 20722 7000;

E-mail: Veli-Pekka.Kallberg@vtt.fi level crossing and the driver being in a hurry. Among the environmental factors, the most general background factors included the rising gradient of the road to the level crossing, the slipperiness of the road and obstructed sightline. Further factors hampering observation were glare caused by sunshine, fog, darkness and the road-railway crossing angle.

The Finnish Transport Agency (until 1.1.2010 Finnish Rail Administration RHK), which manages the Finnish rail infrastructure, is mainly responsible for the equipment, condition and safety of level crossings. Although almost all level crossing accidents result from inappropriate and incautious behaviour of road users, it is in the Finnish Transport Agency's best interests to ensure that the conditions at level crossings are safe and support as best as possible the correct behaviour of road users. Therefore in 1999 the RHK commissioned VTT to start systematic safety audits at level crossings on the state railway network. Since then the audits have continued at an average pace of about 400 level crossings per year, so that by the end of 2008 the total number of inspected level crossings was 3863 . The total number of inspected level crossings exceeds the current number of level crossings on the state railways because several inspected level crossings have been removed and 148 level crossings have been audited for a second time.

Systematic inspections of level crossings come under overall level crossing management also in other countries. In the United Kingdom, Network Rail has comprehensive checklists to ensure that level crossing systems are safe, reliable and legally compliant [4]. In the United States, the Federal Railway Administration uses a specific form for level crossing inventories [5].

The objective of the safety audits is to improve safety at level crossings. More specifically, the audits result in recommendations that aim to enhance conditions for safe crossing of the railway for vigilant and motivated road users. 
The objective of this paper is to provide a general description of the audit method and the results of the audits.

\section{METHOD}

The safety audits at level crossings are based on systematic and extensive at-site recording of the physical characteristics of the level crossing, including:

- $\quad$ Location of level crossing

- $\quad$ Number of railway tracks

- $\quad$ Distance between outermost tracks

- $\quad$ Speed limit of trains

- $\quad$ Number of trains per day

- $\quad$ Road category

- $\quad$ Traffic volume on the road

- $\quad$ Speed limit on the road

- Active warning devices (barriers, light and sound warning devices)

- Warning signs for road traffic (e.g. crossbucks, stopsigns)

Advance warning signs for road traffic

Estimated maximum traversing speed for heavy vehicle combinations (typically 10, 20, $30 \mathrm{~km} / \mathrm{h}$ )

Structure of the level crossing surface

Nearby road junctions, if any

Measured sight distances from the road $(8 \mathrm{~m}$ from the nearest rail) to the railway, to the left and right of both approach directions.
- $\quad$ Estimated sight distances after clearing of visibilityrestricting vegetation from the road $(8 \mathrm{~m}$ from the nearest rail) to the railway, to the left and right of both approach directions.

A number of digital photographs are taken at fixed locations in following directions:

- $\quad$ From the road, $8 \mathrm{~m}$ from the nearest rail, left and right

- $\quad$ From the road, $25 \mathrm{~m}$ and $50 \mathrm{~m}$ from the railway, toward the level crossing

- From the track, $30 \mathrm{~m}$ and $100 \mathrm{~m}$ from the level crossing, towards the level crossing

GPS and inclinometer devices are used to trace the lateral and vertical profile of the road surface near the crossing (Fig. 1).

Recent inspections also contain video clips describing how visibility from the road to the track changes as the road vehicle approaches the level crossing (Fig. 2).

At-site observations are analysed back in the office. The physical features of the level crossing are compared with existing guidelines [6], and recommendations are made for the removal of inconsistencies. Furthermore and most importantly, the auditors assess whether the conditions at the level crossing are such that safe traversing is possible for vigilant and motivated road users. The main criterion for such assessment is to decide whether road users can traverse the level crossing in less time than it takes for an approaching train to arrive at the level crossing from the point where the road user who has stopped in front of the level crossing can first see it. The traversing time depends on the road user type, and in the safety audits the required traversing times are determined for three vehicle categories:

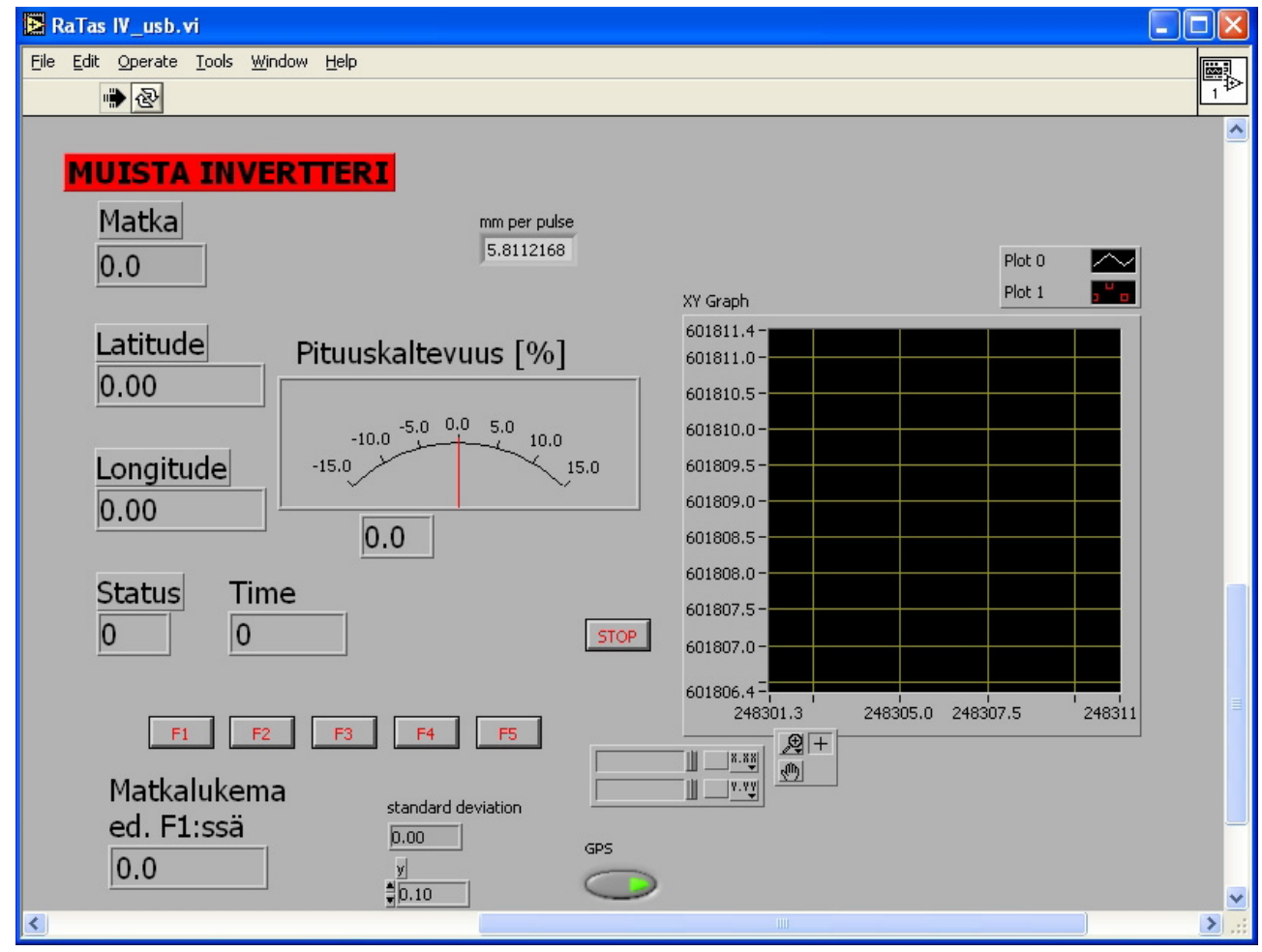

Fig. (1). Display on a road-alignment measuring device. 


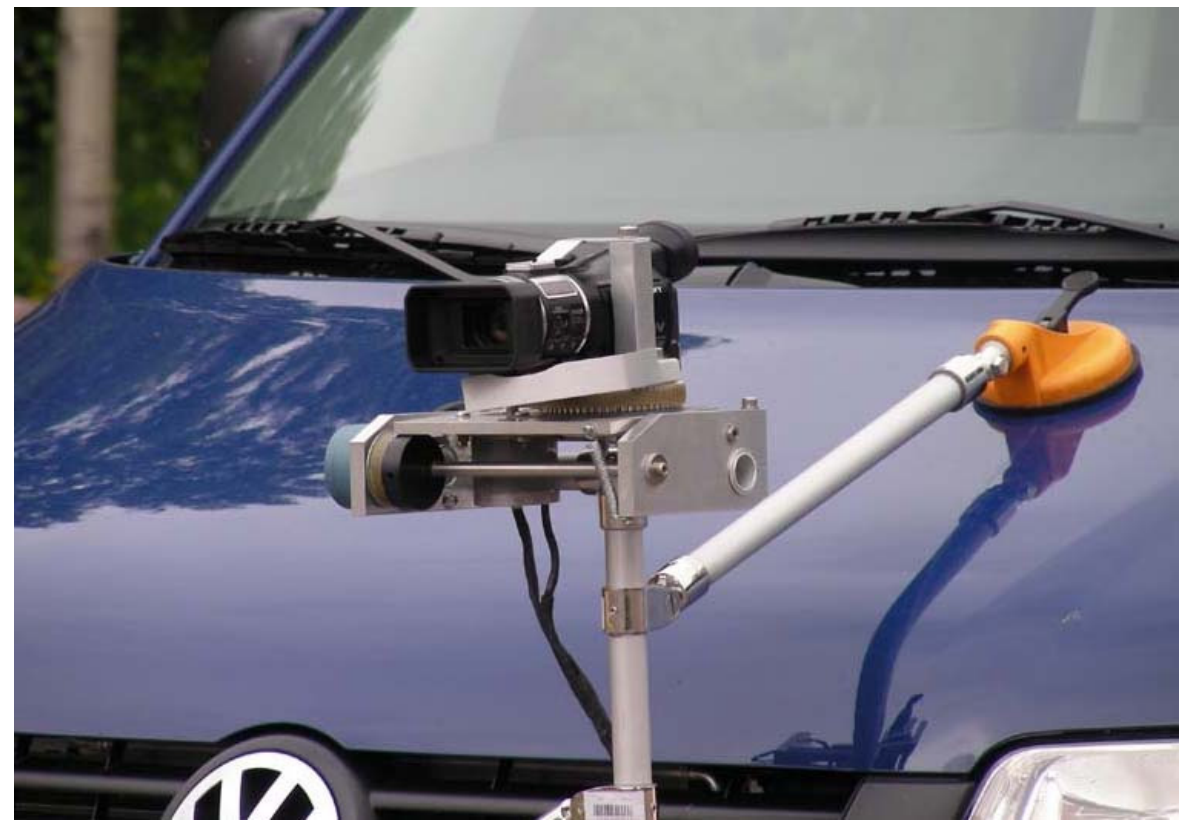

Fig. (2). Video camera mounted in front of the vehicle. The camera is operated from the cabin; the recording describes how visibility towards the railway improves as the vehicle approaches the level crossing.

cars, $12 \mathrm{~m}$ long lorries and $25.25 \mathrm{~m}$ long lorries and trailer combinations. In practice the required crossing times are determined from Table 1, which is based on a large number of simulations with an advanced vehicle movement simulator called Vemosim [7].

The focus was on the provision of conditions enabling safe traversing of the level crossings. The recommendations for safety improvements concern mainly measures under the jurisdiction of the rail infrastructure manager. Consequently, most recommendations deal with the physical conditions and equipment (such as warning devices) at level crossings. Where human factors are concerned, it was assumed that road users are vigilant and willing to behave safely. It is recognised that this is not always the case, but further consideration of human factors was outside the scope of the audits.

Available crossing times were calculated by dividing the measured sight distance $(\mathrm{m})$ from the road to the track $(8 \mathrm{~m}$ from the nearest rail) by maximum allowed train speed $(\mathrm{m} / \mathrm{s})$.

\section{RESULTS}

The results of the safety audits are described in reports prepared for different railway sections. In total 45 such reports have been prepared so far. Each report provides summary descriptions of the general condition of the level crossings on that particular railway section, such as maps of the locations, existence of active and passive warning devices, sight distance conditions and vertical alignment of the road near the level crossing. Recommendations for safety improvements are presented for each level crossing separately, but they are also summarised in a table. Detailed descriptions of each level crossing are tabulated in the annexes of the report.

Figs. $(3,4)$ are an example of a brief description of a level crossing in the audit reports. The main features of the level crossing are summarised in photographs taken at fixed locations. The address and name of the level crossing are in the top left corner of Fig. (3). The estimated traversing times for a $25.25 \mathrm{~m}$ long truck and trailer combination and a car are 17 seconds and 5 seconds respectively, and in this case they are the same in both directions. The required sight distance in the guidelines [6] in metres is 6 times the maximum train speed in $\mathrm{km} / \mathrm{h}$, in this case $6 \times 140=840 \mathrm{~m}$. This corresponds to an actual traversing time of 21.6 seconds, which is usually long enough even for heavy truck and trailer combinations starting from standstill $8 \mathrm{~m}$ from the nearest track. Even after clearing of vegetation, the sight distances from the west to the right and from the east to the left remain shorter than required. The shortest sight distance of $350 \mathrm{~m}$ after clearing of vegetation means that if there is no train in sight, road users have at least 9 seconds to traverse the track. This is enough for cars but not for truck and trailer combinations. The recommended measures in this case were clearing of vegetation and a driving ban for truck and trailer combinations.

Overall, 95,6\% of level crossing inspections resulted in recommendations for improvements. The total number of recommended safety measures for the 3715 level crossings, which were inspected for the first time, was 7 598. Clearing of visibility-restricting vegetation was recommended for three-quarters of all level crossings (Table 2). Improvement of the vertical alignment of the road, a driving ban for long vehicle combinations and removal of the level crossing were also frequently mentioned safety measures.

The measures described in Table $\mathbf{2}$ are elaborated further in the following:

Clearing of sight-restricting vegetation should be carried out regularly in the summertime (Fig. 6). Clearing is usually possible only in the railway area, and it is not always possible to remove bushes and trees on private land. 
Table 1. Required Traversing Times

\begin{tabular}{|c|c|c|c|c|}
\hline \multirow{2}{*}{ Maximum Traversing Speed $(\mathbf{k m} / \mathbf{h})$} & \multirow{2}{*}{ Vertical Alignment of $\operatorname{Road}^{1}$} & \multicolumn{3}{|c|}{ Traversing Time (s) } \\
\hline & & Car & 12 m Long Lorry & $25.25 \mathrm{~m}$ Long Lorry \& Trailer \\
\hline \multirow{6}{*}{5} & $>0 \mathrm{~m}$ & 5 & 14 & 28 \\
\hline & $0-0.5 \mathrm{~m}$ & 5 & 14 & 28 \\
\hline & $0.5-1.0 \mathrm{~m}$ & 5 & 14 & 28 \\
\hline & $1.0-1.5$ & 5 & 14 & 28 \\
\hline & $1.5-2.0 \mathrm{~m}$ & 5.5 & 14 & 28 \\
\hline & $>2.0 \mathrm{~m}$ & 5.5 & 14 & 28 \\
\hline \multirow{6}{*}{10} & $>0 \mathrm{~m}$ & 4.5 & 9 & 16 \\
\hline & $0-0.5 \mathrm{~m}$ & 5 & 10 & 18 \\
\hline & $0.5-1.0 \mathrm{~m}$ & 5.5 & 11 & 19 \\
\hline & $1.0-1.5$ & 5.5 & 11 & 20 \\
\hline & $1.5-2.0 \mathrm{~m}$ & 5.5 & 11 & 20 \\
\hline & $>2.0 \mathrm{~m}$ & 5.5 & 12 & 21 \\
\hline \multirow{6}{*}{20} & $>0 \mathrm{~m}$ & 4 & 7 & 13 \\
\hline & $0-0.5 \mathrm{~m}$ & 5 & 8 & 15 \\
\hline & $0.5-1.0 \mathrm{~m}$ & 5 & 8 & 17 \\
\hline & $1.0-1.5$ & 5 & 8 & 18 \\
\hline & $1.5-2.0 \mathrm{~m}$ & 5 & 8 & 19 \\
\hline & $>2.0 \mathrm{~m}$ & 5 & 9 & 20 \\
\hline \multirow{6}{*}{ At least 30} & $>0 \mathrm{~m}$ & 4 & 6 & 12 \\
\hline & $0-0.5 \mathrm{~m}$ & 4 & 7 & 14 \\
\hline & $0.5-1.0 \mathrm{~m}$ & 4.5 & 7 & 16 \\
\hline & $1.0-1.5$ & 4.5 & 7 & 17 \\
\hline & $1.5-2.0 \mathrm{~m}$ & 4.5 & 7 & 18 \\
\hline & $>2.0 \mathrm{~m}$ & 4.5 & 8 & 19 \\
\hline
\end{tabular}

Difference between the height of the road centreline at the level crossing and at $30 \mathrm{~m}$ from the nearest rail.

- The railway is often on a bank and the approach to the level crossing is steeply uphill, especially on minor rural roads (Fig. 7). Improvement of the road alignment is sometimes not possible without major reconstruction, especially when there is a road parallel to and very near the railway.

- Implementation of barriers or other expensive measures are seldom feasible for minor roads with little traffic.

- $\quad$ A speed limit for trains is usually a last resort when nothing else works.

- Driving bans for certain types of road vehicles are feasible only when it is unlikely that such vehicles must use the level crossing.

- Level crossings can be removed only if traffic can use other existing or new routes, or the level crossing is not used at all (Fig. 8). Removal of existing level crossings also requires administrative procedures, which can be laborious.
- $\quad$ The recommendations were categorised according to urgency: they should be implemented immediately (which can sometimes take a year or two), soon (within a few years) or later. Immediate measures like a speed limit for trains can sometimes be cancelled when e.g. barriers are installed. Ninety percent of the measures were assigned in the first category (e.g. clearing of vegetation), $8 \%$ in the second (e.g. installation of half-barriers), and $2 \%$ in the third (e.g. construction of a grade-separated crossing).

- $\quad$ Measures which were recommended for less than 3\% of the audited level crossings included e.g. installation of stop signs, mirrors, whistling signs for trains, building of chicanes at pedestrian and bicycle crossings, installation of locked gates and installation of portals or similar measures that make the level crossing more visible to road users.

I addition to the reports, a computer program is maintained that enables easy viewing of the main features, photographs and for recently audited level crossings also video clips of each level crossing (Fig. 5). 


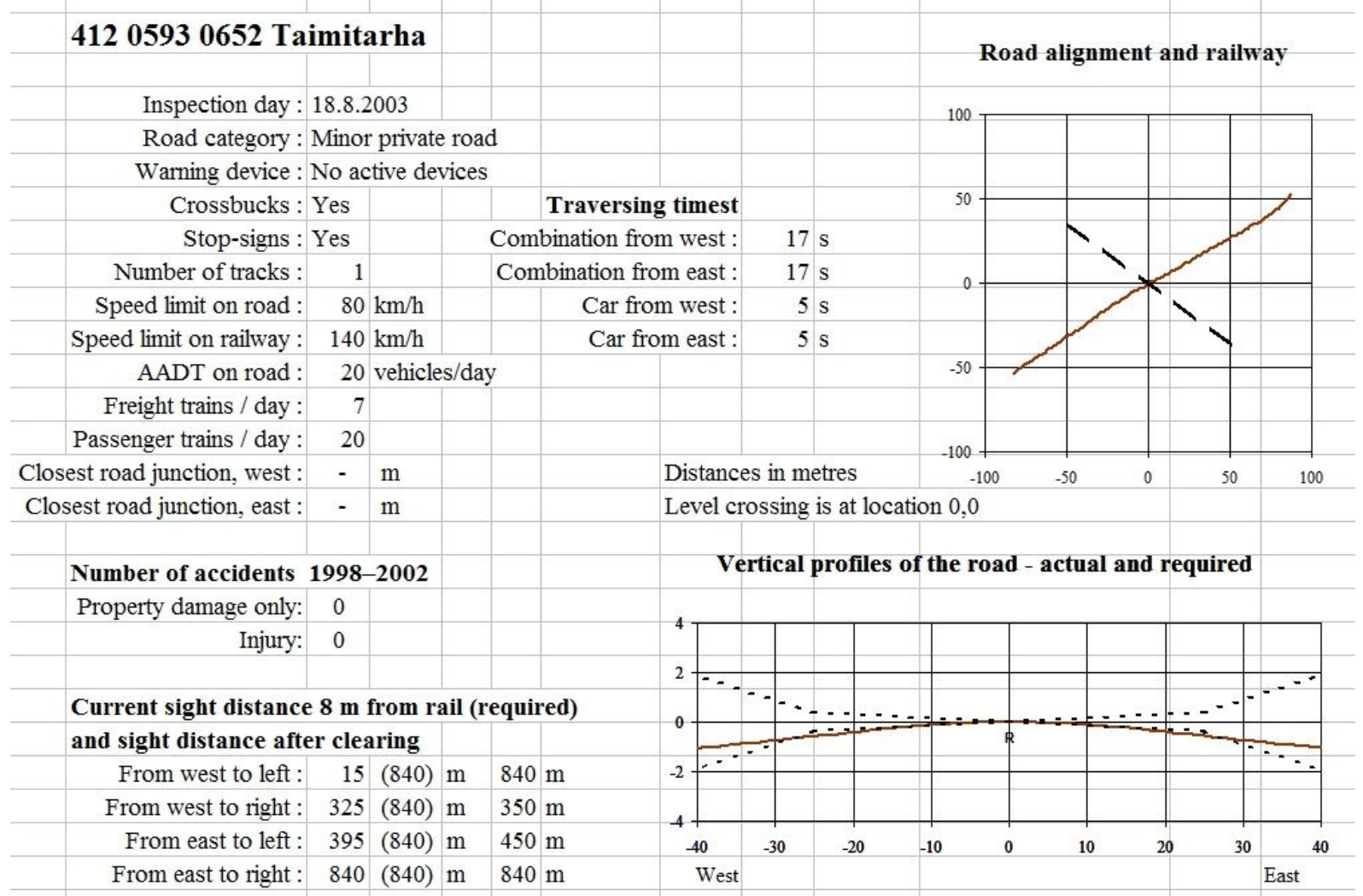

Fig. (3). Brief description of the main elements of level crossings used in the reports.

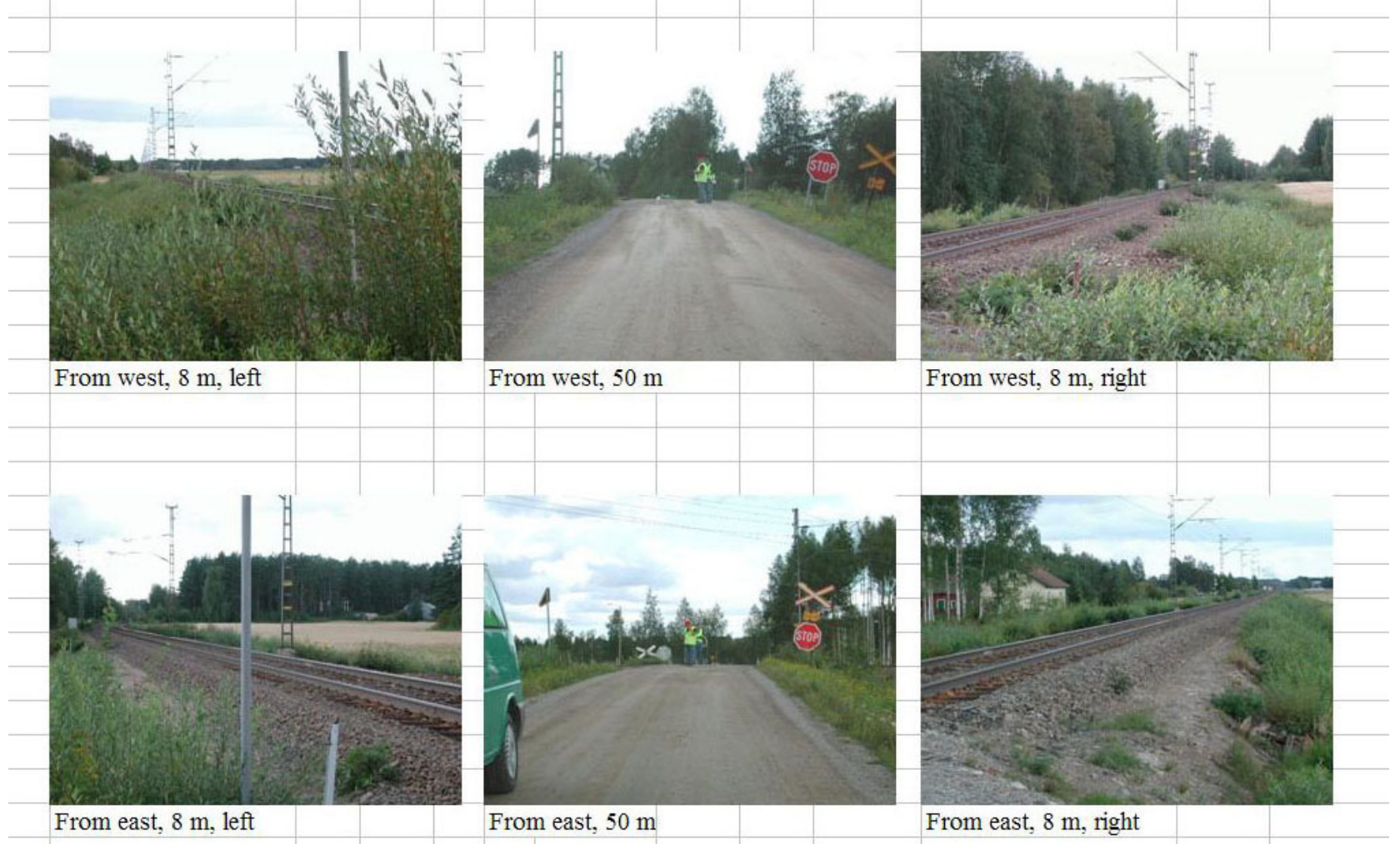

Fig. (4). Standard presentation of photographs in the audit reports.

The recommended measures typically improve the conditions for safe traversing, and thus make it easier for road users to avoid collisions with trains. However, no studies have been conducted that describe the impacts of various implemented measures on actual road user behaviour. 


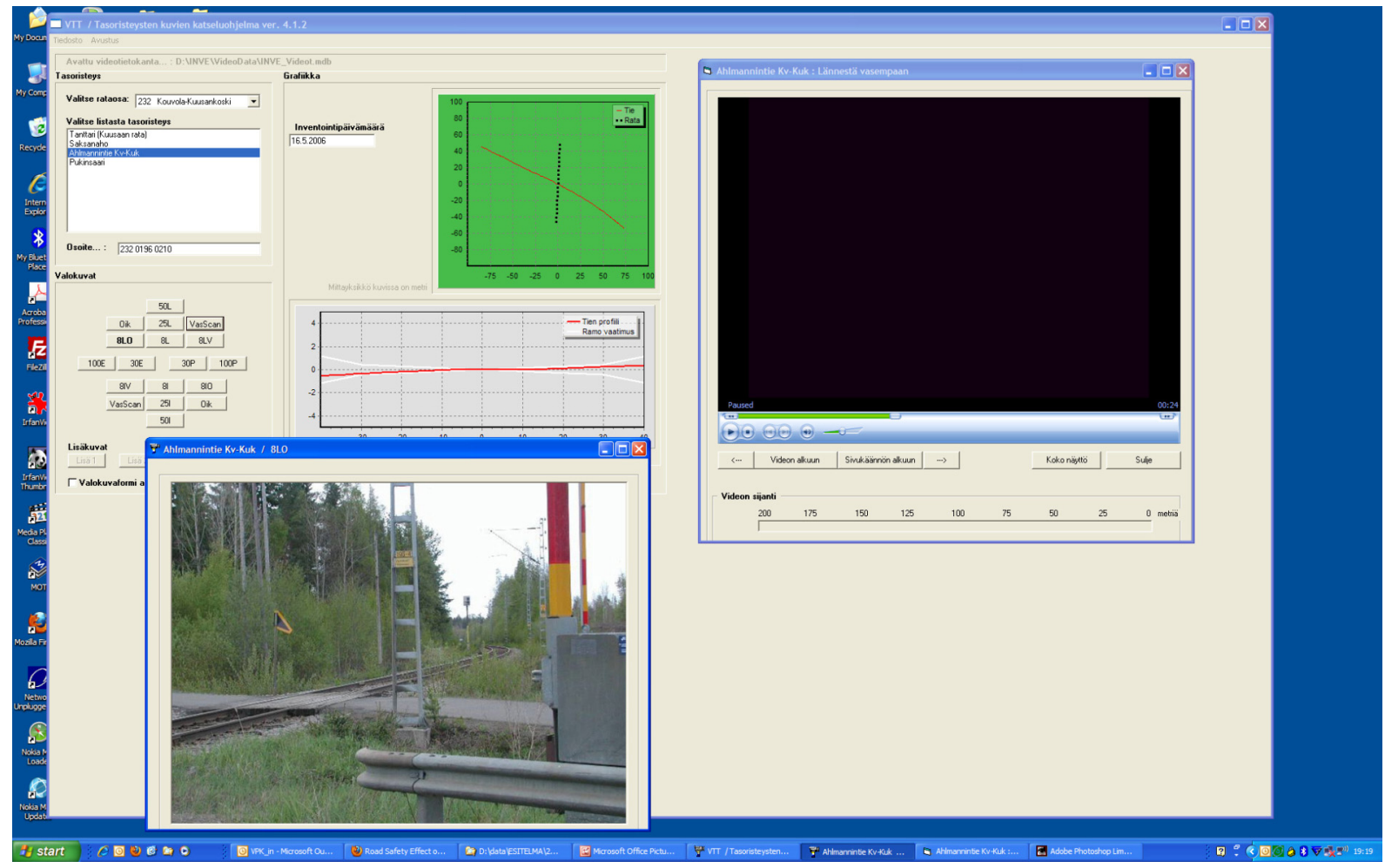

Fig. (5). Display of PC application for viewing of level crossing conditions.

Table 2. Safety Measures Recommended for At Least 3\% of Audited Level Crossings

\begin{tabular}{|c|c|c|}
\hline \multicolumn{2}{|c|}{ Measure } & Proportion of Level Crossings \\
\hline \hline 1 & Clearing of vegetation & $77 \%$ \\
\hline 2 & Improvement of vertical alignment of the road & $22 \%$ \\
\hline 3 & Driving ban for lorry and trailer combinations & $18 \%$ \\
\hline 4 & Removal of level crossing & $16 \%$ \\
\hline 5 & Installation of crossbuck signs & $9 \%$ \\
\hline 6 & Renewal of level crossing deck & $8 \%$ \\
\hline 7 & Removal of level crossing and building of a new road connection & $8 \%$ \\
\hline 9 & Driving ban for lorries and buses & $6 \%$ \\
\hline 9 & Reduced spot speed limit for trains & $4 \%$ \\
\hline 10 & Installation of half-barriers & $4 \%$ \\
\hline 11 & Installation of a sand bin (for icy road conditions) & $3 \%$ \\
\hline 12 & Construction of a grade-separated crossing & \\
\hline
\end{tabular}

\section{DISCUSSION AND CONCLUSIONS}

The conducted safety audits have revealed significant deficiencies in the safety of level crossings. Consequently, inspections have shown to be an effective tool to identify safety problems of level crossings and help create conditions where safe crossing is possible.

Most deficiencies in the safety of level crossings seem to concern less than adequate sight distances. Sometimes clearing of vegetation can restore the required visibility, but in other cases long and slow vehicles must be banned from using the level crossing or the speed limit of trains must be reduced to guarantee safe traversing conditions for road traffic.

Even though sight distances from the road to the railway are often shorter than required in the guidelines, they contribute somewhat infrequently to level crossing accidents. One reason for this may be that according to the current guidelines the sight distance from the road $(8 \mathrm{~m}$ from the nearest rail) in metres must be at least six times the maximum speed of the train in $\mathrm{km} / \mathrm{h}$, which guarantees a $21.6 \mathrm{~s}$ traversing time for road users (for level crossings of a single railway track). Because in most vehicles the actual traversing is much shorter, the current guidelines have a considerable built-in safety margin. Furthermore, road users 


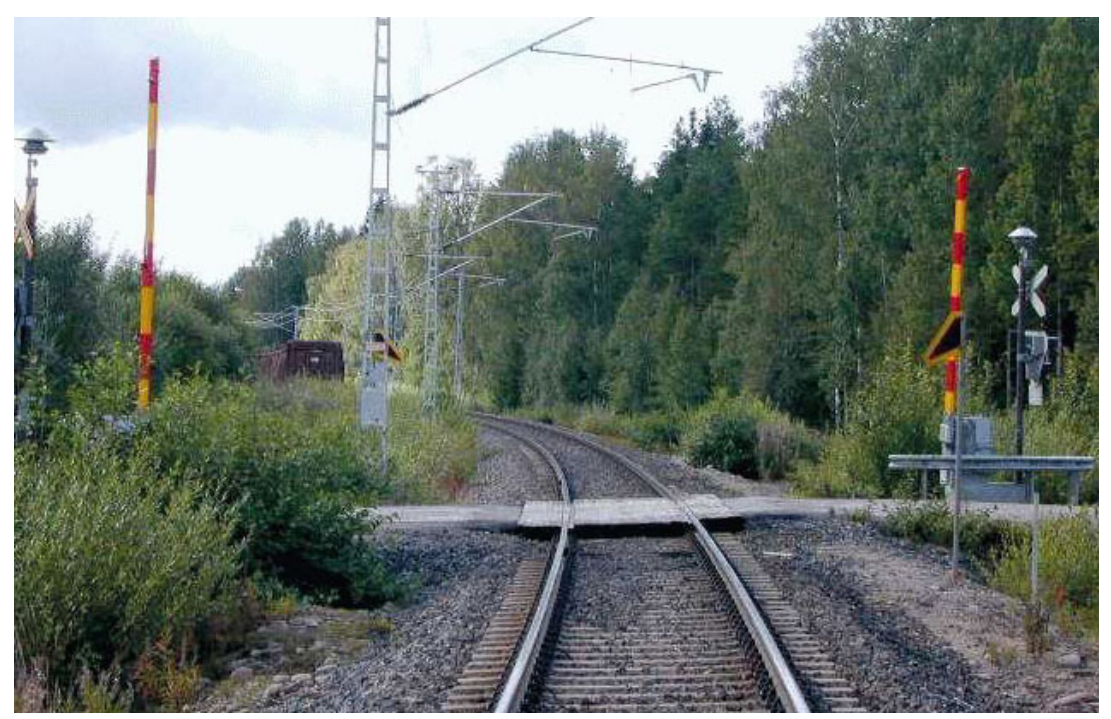

Fig. (6). Sight-restricting vegetation.

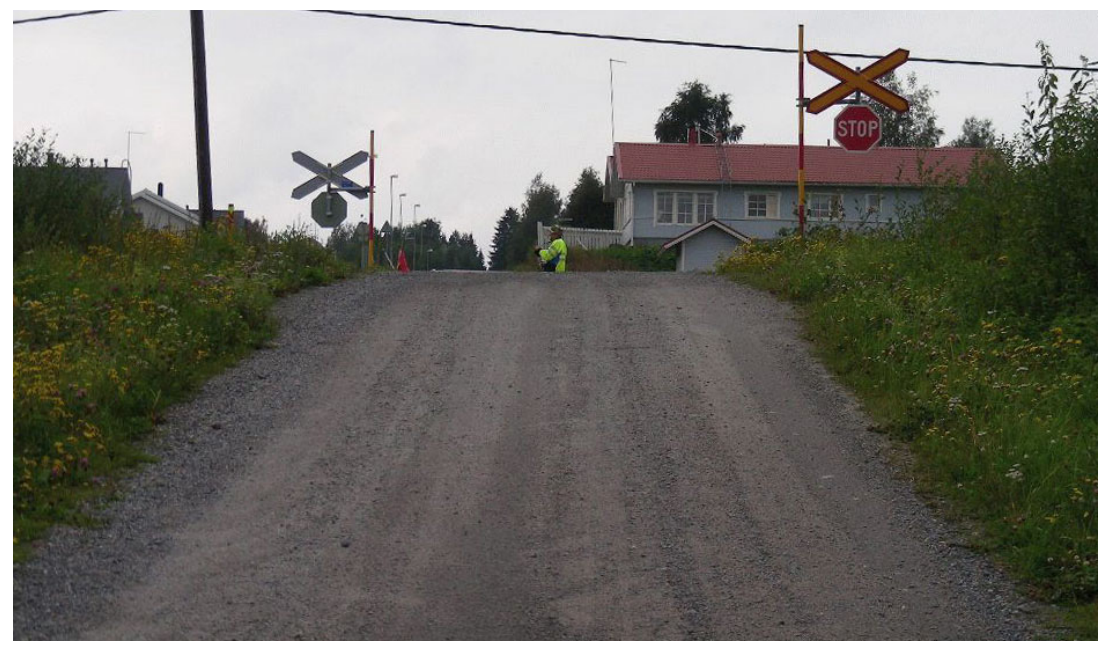

Fig. (7). Steep approach to a level crossing.

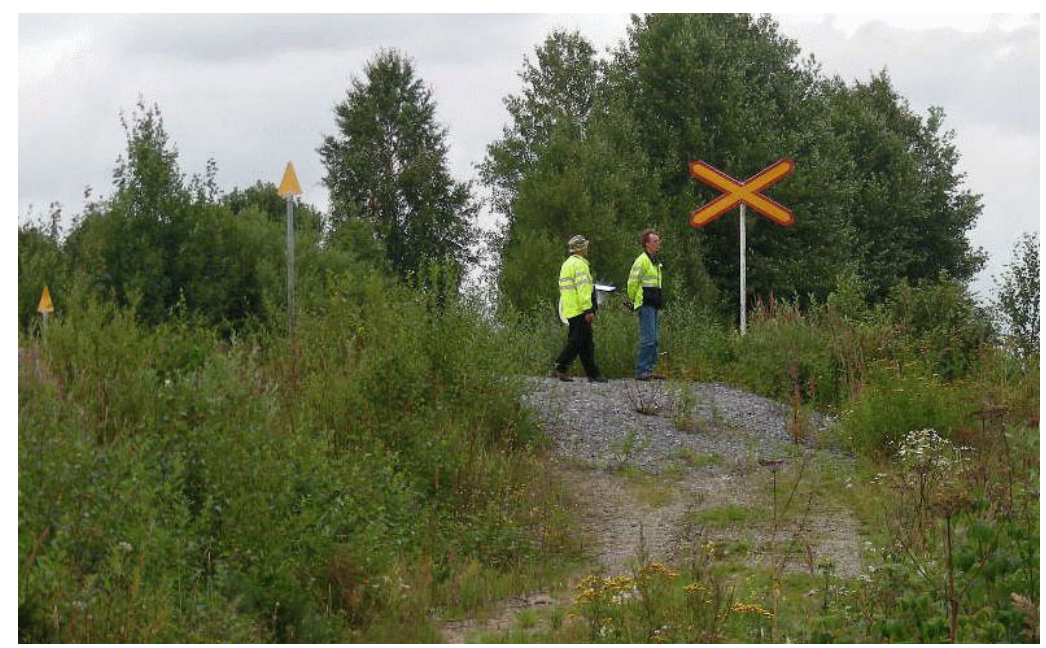

Fig. (8). A desolate level crossing clearly not in active use.

can often make the decision to cross the railway closer to the track than $8 \mathrm{~m}$, where the visibility to the railway is usually longer than that measured according to the guidelines.
Most Finnish level crossings are on minor low-volume private roads, where other than low-cost measures are usually unrealistic. Installation of automatic half-barriers or major improvement of the vertical profile of the road, for example, is rarely a feasible option. 
The implementation of driving bans for lorry and trailer combinations is not always easy either, since there must be another road for such vehicles to their destination across the railway, or it must be clear that there is no need for such vehicles to use the level crossing.

Reduction of the speed limit for trains is only used as a last resort, when no other measures work. The advantage of the reduced speed limit is that it can be implemented quickly. An obvious disadvantage is that it slows down train traffic. A reduced speed limit can often be cancelled later when other measures needing more time to implement, such as half-barriers, have been installed.

The added value of the described inspections is first of all that they provide the infrastructure manager with necessary information for the upgrade of individual level crossings so that crossing the railway is safe for all vigilant and motivated road users. The mere number of recommended, targeted safety measures -7598 for the 3715 level crossings in the first round of audits - is a clear indication of the usefulness of the audits. Furthermore the aggregated results of the audits, which to date have been conducted at almost all level crossings on the state railway network, offer a comprehensive overview of the general condition of Finnish level crossings, which in turn is helpful for long-term strategic planning.

Secondly, the resulting database provides an excellent basis for various statistical analyses in the further promotion of safety at level crossings. For example, the Finnish Transport Agency has used this data to calculate the level crossing index, which is a function of traffic volumes on the railway and road, warning device (e.g. half-barriers), maximum speed of trains and road vehicles, the angle between the road and the railway, vertical alignment of the road, number of tracks and sight distances from the road to the track [6]. The origins of this index are not documented and its validity is unknown, but it is used to describe the safety of level crossings.
Thirdly, the PC application for viewing individual level crossings is a handy tool for the Finnish Transport Agency's personnel responsible for level crossing management, e.g. in case of contacts from the public asking about conditions at or plans concerning certain level crossings.

The resources needed for the audits described in this paper correspond to roughly one person-day per level crossing. Approximately half of the work concerns the collection of data in the field, and the other half concerns analysis and reporting. A team of two to three persons can process approximately 400 level crossings per year.

The safety audit methods and procedures involved have been further developed and streamlined during a decade of application, and nowadays the handling of data, photos and videos is largely automated. It must be emphasised, however, that skilled and trained personnel is the primary prerequisite for successful application of the developed method.

\section{ACKNOWLEDGEMENT}

The safety audits at Finnish level crossings were funded by the Finnish Rail Administration and since January 1, 2010 by the Finnish Transport Agency.

\section{REFERENCES}

[1] Finnish Rail Administration, "The Finnish railway Statistics", 2008.

[2] Statistics Finland, "Traffic accident statistics", 1970-2007.

[3] Onnettomuustutkintakeskus, "Turvallisuusselvitys tasoristeysonnettomuuksista" [Safety study on level crossing accidents], tutkintaselostus S 1/2005 R, in Finnish, English summary, 2005.

[4] Network Rail, "Level Crossing Infrastructure (Inspection \& Maintenance) Handbook", London, 2006.

[5] U.S. Department of Transpoirtation, Federal Highway Administration, "Railroad-Highway Grade Crossing Handbook", 2007.

[6] Finnish Rail Administration, "Ratatekniset määräykset ja ohjeet, osa 9 Tasoristeykset. [Technical guidelines for Finnish railways, part 9 Level crossings]", in Finnish, 2004.

[7] O.H. Koskinen \& J. Sauna-Aho, "Computer simulation of road vehicles for analysing energy consumption, emission amounts, etc", the 5th World Congress on Intelligent Transport Systems, Paper No. 2064, Seoul, Korea, 1998. 